\title{
Molecular Integrity of Mitochondria Alters by Potassium Chloride
}

\author{
Suman Mishra and Rajnikant Mishra \\ Biochemistry and Molecular Biology Lab, Department of Zoology, Banaras Hindu University, Varanasi 221005, India \\ Correspondence should be addressed to Rajnikant Mishra; rmishraa@bhu.ac.in
}

Received 29 September 2015; Revised 7 November 2015; Accepted 10 November 2015

Academic Editor: Setsuko Komatsu

Copyright (C) 2015 S. Mishra and R. Mishra. This is an open access article distributed under the Creative Commons Attribution License, which permits unrestricted use, distribution, and reproduction in any medium, provided the original work is properly cited.

\begin{abstract}
Potassium chloride $(\mathrm{KCl})$ has been commonly used in homogenization buffer and procedures of protein extraction. It is known to facilitate release of membrane-associated molecules but the higher concentration of $\mathrm{KCl}$ may affect the integrity of mitochondria by breaching the electrostatic force between the lipids and proteins. Therefore, it has been intended to explore the effect of $\mathrm{KCl}$ on mitochondrial proteome. The mitochondria were isolated from the mice liver and sub-fractionated into mitochondrial matrix and outer mitochondrial membrane fraction. The fractions were analysed by denaturing polyacrylamide gel electrophoresis (PAGE) and 2D-PAGE. The analysis of ultrastructure and protein profiles by MALDI-MS and data-mining reveals KCl-associated alterations in the integrity of mitochondria and its proteome. The mitochondrial membrane, cristae, and the matrix proteins appear altered under the influence of $\mathrm{KCl}$.
\end{abstract}

\section{Introduction}

Mitochondria, the power house of the cell, are double membrane-bound organelle. The membranes provide compartmentalization to biomolecules and critically regulate physiological functions of organelles and cells. Among macromolecules of membranes, both extrinsic (peripheral) and intrinsic (integral) proteins show more variability. Mostly, integral proteins serve as transporters or receptors and their extraction has been facilitated by ionic detergents [1] Peripheral proteins remain loosely associated with membrane by ionic or hydrogen bonding and function as specific transporters to regulate homeostasis of metabolites. Conventionally, salts (monovalent and divalent) and nonionic or milddetergents have been used in the homogenizing medium for extraction of proteins of plasma membrane and membranes of cell organelles but they may also induce swelling of lipid layer [2-4] and change in ionic permeability [5-7]. Since mitochondria are enriched with proteins regulating several critical metabolic processes like oxidative phosphorylation, redox reactions, fatty acid synthesis, $\beta$-oxidation, and citric acid cycle, the isolation procedure of mitochondria for basic or clinical studies would bear large impact on the activities of enzymes and proteins. Therefore, it has been intended to explore the effect of $\mathrm{KCl}$ on integrity of mitochondrial membrane. Results provide insight on $\mathrm{KCl}$-associated influences on integrity of mitochondria and leakage of mitochondrial matrix protein.

\section{Materials and Methods}

2.1. Animals, Materials, and Isolation of Mitochondria and Mitochondrial Membrane-Bound Fraction. The adult mice (Mus musculus) of AKR strain were maintained with standard mice feed and drinking water at $25 \pm 2^{\circ} \mathrm{C}$ in animal house facility of the department as per guidelines of the Institutional Animal Ethical Committee. Animals were sacrificed to obtain liver. All analytical grade chemicals were used. The $20 \%$ homogenate of liver was prepared in homogenizing buffer containing $30 \mathrm{mM}$ Tris $\mathrm{HCl}$ (pH 7.2), $1 \mathrm{mM}$ EDTA, $250 \mathrm{mM}$ Sucrose, $50 \mathrm{mM}$ Mannitol, and protease inhibitor cocktail (Sigma-Aldrich) using a Potter-Elvehjem type glass homogenizer with a motor-driven teflon pestle. Cytosolic and Mitochondrial fractions were isolated first without $\mathrm{KCl}$ in homogenizing medium and mitochondrial pellet was washed with 


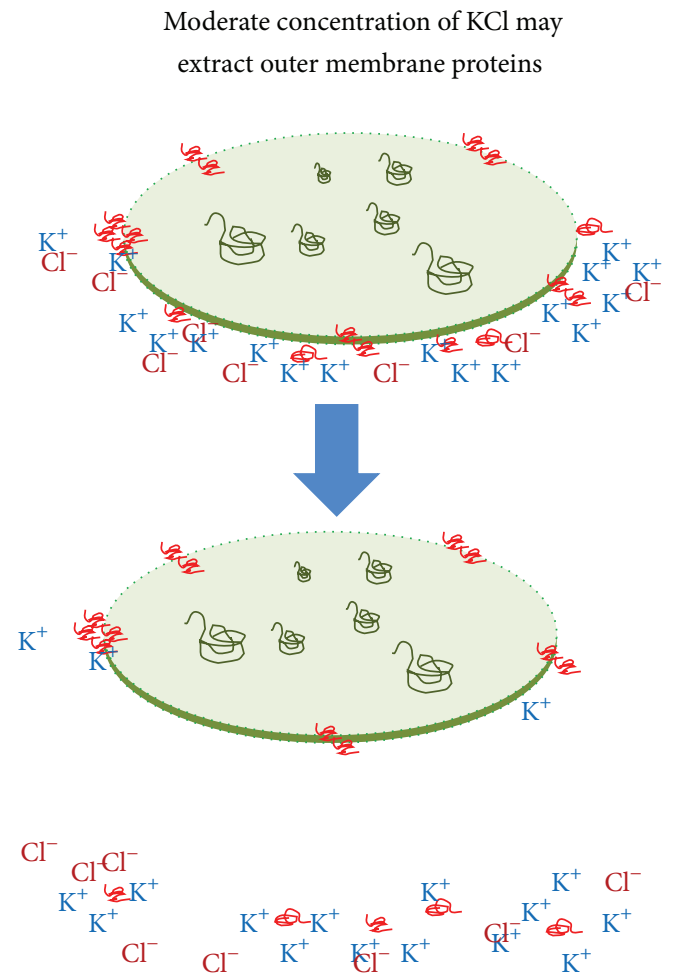

(a)
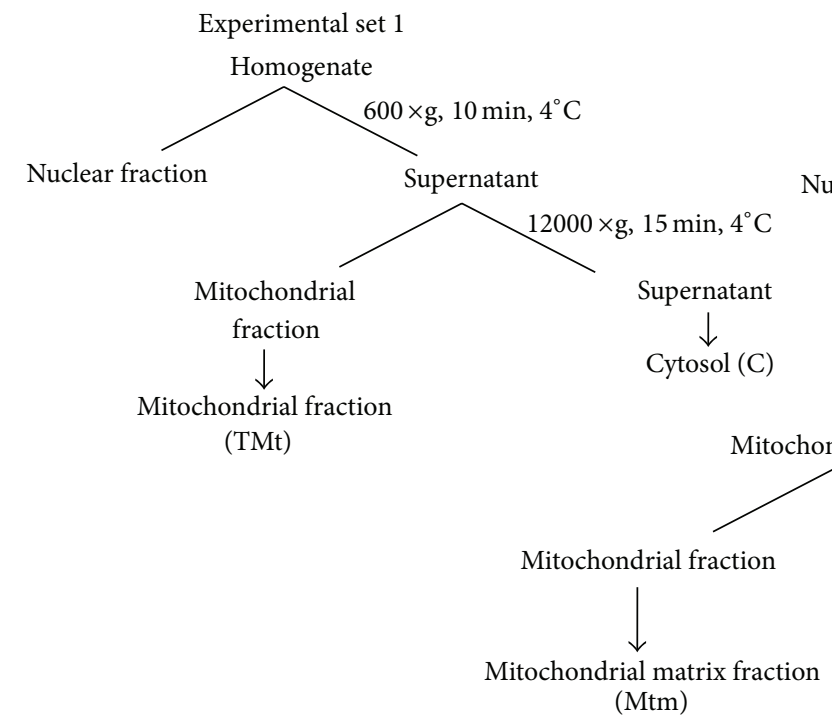

(b)
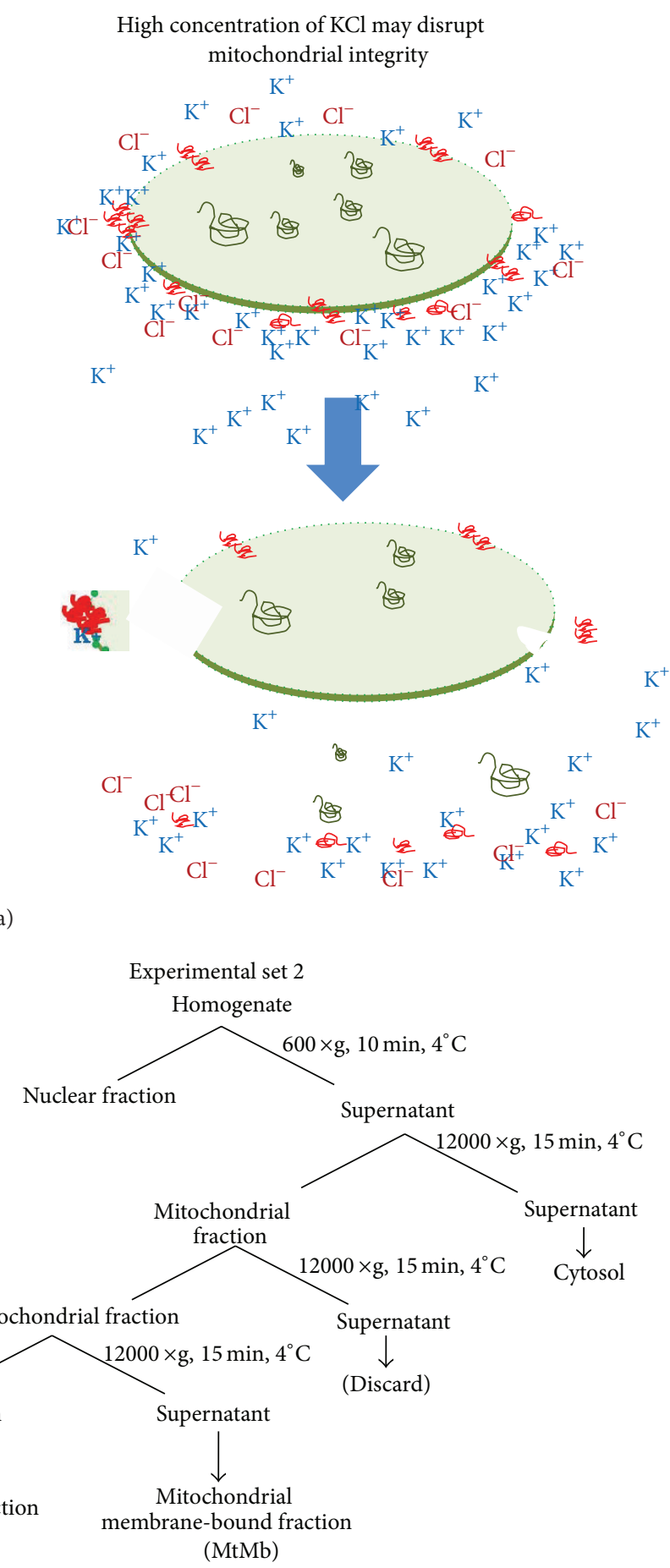

(MtMb)

FIGURE 1: (a) demonstrates effect of $\mathrm{KCl}$ concentration on mitochondrial membrane. (b) Flowchart describes method of fractionation to study the effect of $\mathrm{KCl}$ concentration.

homogenization buffer. Washed mitochondrial pellet was suspended in different concentrations of $\mathrm{KCl}(25 \mathrm{mM}$, $50 \mathrm{mM}, 100 \mathrm{mM}, 150 \mathrm{mM}$, and $200 \mathrm{mM}$ ) in homogenizing medium. Then, mitochondrial outer membrane-bound fraction (MtMb) and mitochondrial fractions (Mtm) were separated (Figure 1(b)). These fractions were used for protein profile analysis. Protein was estimated by the method of Bradford [8].

2.2. Protein Profile of Mitochondria and Mitochondrial Membrane-Bound Fractions. In order to analyse the influence of the concentration of $\mathrm{KCl}$ on the integrity of 


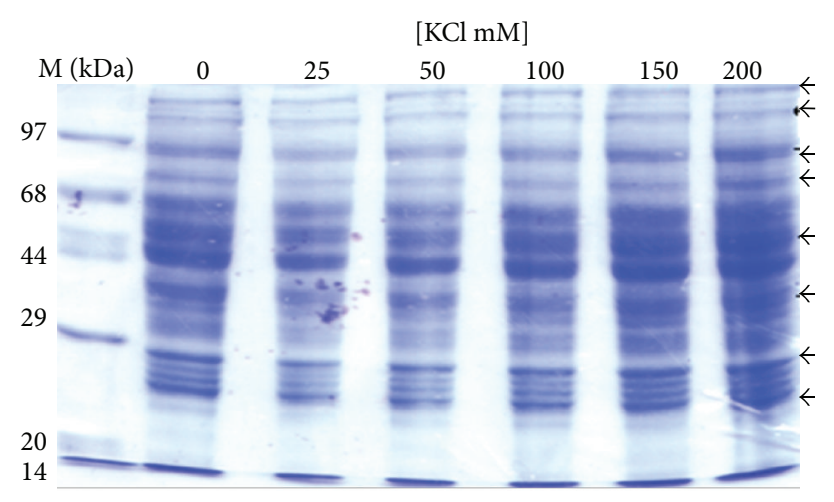

FIGURE 2: Effect of concentration of $\mathrm{KCl}$ on protein profile of cytosolic fraction (set 1). The protein profile of cytosolic fraction indicates the release of the membrane proteins showing increased intensity of bands near to $110 \mathrm{kDa}, 97 \mathrm{kDa}, 70 \mathrm{kDa}, 68 \mathrm{kDa}, 44 \mathrm{kDa}, 38 \mathrm{kDa}, 28 \mathrm{kDa}$, $25 \mathrm{kDa}$, and $23 \mathrm{kDa}$. The increase in intensity of these bands was probably due to protein released from the membrane of mitochondria and other subcellular organelles.

mitochondria and mitochondrial membrane-bound proteins, two sets of experiments were performed (Figure 1(b)). In first set (E1), different concentrations of $\mathrm{KCl}(0,25 \mathrm{mM}$, $50 \mathrm{mM}, 100 \mathrm{mM}, 150 \mathrm{mM}$, and $200 \mathrm{mM}$ ) were used in homogenizing medium, and mitochondrial and cytosolic fractions were isolated, respectively. In second set (E2), mitochondria were isolated without $\mathrm{KCl}$ in homogenizing medium and mitochondrial pellet was washed twice with homogenization buffer to remove any cytosolic fraction. The mitochondrial pellet was then suspended in homogenizing medium containing $25 \mathrm{mM}, 50 \mathrm{mM}, 100 \mathrm{mM}, 150 \mathrm{mM}$, and $200 \mathrm{mM} \mathrm{KCl}$ and mitochondrial membrane-bound fraction and mitochondrial fraction were separated, respectively. Proteins from different fractions were resolved on $15 \%$ denaturing polyacrylamide gel electrophoresis (SDS-PAGE) and proteins were visualized by CBB-R250 staining.

2D gel electrophoresis was performed to study the effect of $\mathrm{KCl}$ concentration on mitochondrial protein profile of the different fractions of the mitochondria. For 2D analysis the $100 \mathrm{mM} \mathrm{KCl}$ was selected because this concentration was found moderate and used in various extraction methods. The proteins of total mitochondria (before washing with $100 \mathrm{mM}$ $\mathrm{KCl}$ ), mitochondrial matrix (pellet of mitochondrial matrix after separating mitochondrial membrane), and mitochondrial membrane-bound fraction (supernatant after washing with $100 \mathrm{mM} \mathrm{KCl}$ ) were precipitated with cold acetone and centrifuged at $3000 \times \mathrm{g}$ for $5 \mathrm{~min}$. The pellets were air-dried to remove the acetone. The proteins were solubilised in $0.125 \mathrm{~mL}$ of rehydration buffer (Bio-Rad 163-2106) and the sample was loaded on IPG strips $7 \mathrm{~cm}, \mathrm{pH}$ 3-10 (Bio-Rad, 163-2000) gel in a side-down manner. The sample loaded strips were rehydrated for $12 \mathrm{hrs}$ at $20^{\circ} \mathrm{C}$. The rehydrated strips were focused in Protean i ${ }^{12}$ IEF cell (Bio-Rad cat number 1646002). The focused strips were equilibrated in equilibrating buffers I and II (Bio-Rad, 163-2107 and 163-2108) for $15 \mathrm{~min}$ each. The equilibrated strips were resolved in 10\% denaturing-gel and proteins were visualized by silver staining. The gels were scanned and protein spots were analyzed by using PDQuest software version 7.1 (Bio-Rad) that include spot detection, quantification, background subtraction, and spot matching between multiple gels. Total spot intensity per gel was used to normalize spot intensities to compensate for variations between gel replicates. The relative spot volumes corresponding to total mitochondria (TMt), mitochondrial matrix (Mtm), and outer mitochondrial membrane-bound fraction $(\mathrm{MtMb})$ were compared using Student's $t$-test. $p$ values less than 0.05 were considered statistically significant. Likewise, the SDS-PAGE were analysed by Quantity One software (Bio-Rad) that includes band detection, quantification, background subtraction, and molecular weight prediction on the basis of standard molecular weight markers.

2.3. Analysis of Unique Protein Spot by MALDI/MSMS. The in-gel trypsin digestion of selected spot was performed before the MALDI analysis. The selected spot was excised and destained in washing solution containing $100 \mathrm{mM}$ ammonium bicarbonate and acetonitrile $(1: 1 \mathrm{vol} / \mathrm{vol})$. After destaining, spot was dehydrated in acetonitrile. The gel pieces were rehydrated and reduced in $10 \mathrm{mMDTT}$ and incubated at $50^{\circ} \mathrm{C}$ for $30 \mathrm{~min}$. After reduction, proteins spots were alkylated with $50 \mathrm{mM}$ iodoacetamide in $100 \mathrm{mM}$ ammonium bicarbonate buffer and incubated at room temperature for $30 \mathrm{~min}$. Gel pieces were again washed and digested overnight at $37^{\circ} \mathrm{C}$ in trypsin solution $(25 \mathrm{ng} / \mu \mathrm{L}$ in $25 \mathrm{mM}$ ammonium bicarbonate buffer). The peptides were extracted in extraction buffer $(100 \%$ acetonitrile and $1 \%$ TFA in water, $1: 1 \mathrm{vol} / \mathrm{vol})$, suitably concentrated and analysed through MALDI MS/ MS. Data generated were screened through MASCOT database (http://www.matrixscience.com/) and Panther software (http://www.pantherdb.org/).

2.4. Ultrastructural Evaluation of Mitochondria. The mitochondrial pellets of control (isolated without $\mathrm{KCl}$ ) and $\mathrm{KCl}$ treated fractions (isolated with $100 \mathrm{mM} \mathrm{KCl}$ ) were fixed in $2.5 \%$ glutaraldehyde and $1 \%$ paraformaldehyde in phosphate buffer ( $\mathrm{pH} 7.5)$ at $4^{\circ} \mathrm{C}$ overnight. The fixed mitochondrial pellets were dehydrated through grades of alcohol (30\% to absolute alcohol), and the preparation of block, sectioning, and staining for TEM analysis was executed at AIIMS, New Delhi. The images were further analysed by ImageQuant software (GE healthcare). 


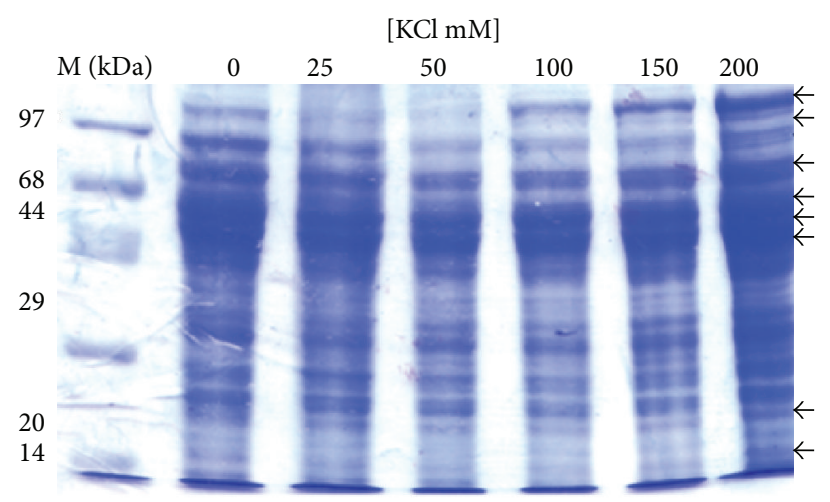

FIGURE 3: Effect of concentration of $\mathrm{KCl}$ on protein profile of mitochondrial fraction (set 1). The mitochondrial fraction shows decrease in intensity of polypeptides $110 \mathrm{kDa}, 97 \mathrm{kDa}, 70 \mathrm{kDa}, 68 \mathrm{kDa}, 66 \mathrm{kDa}, 44 \mathrm{kDa}, 20 \mathrm{kDa}$, and $14 \mathrm{kDa}$ with increasing KCl concentration.

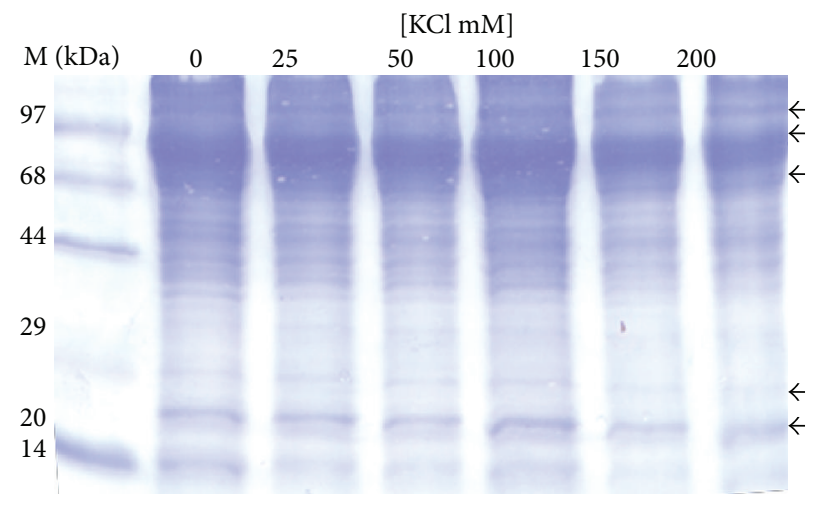

FIGURE 4: Effect of concentration of $\mathrm{KCl}$ on protein profile of mitochondrial matrix fraction (set 2). The protein profile of mitochondrial fraction shows decrease in intensity of some bands of $110 \mathrm{kDa}, 96 \mathrm{kDa}, 70 \mathrm{kDa}, 23 \mathrm{kDa}$, and $20 \mathrm{kDa}$.

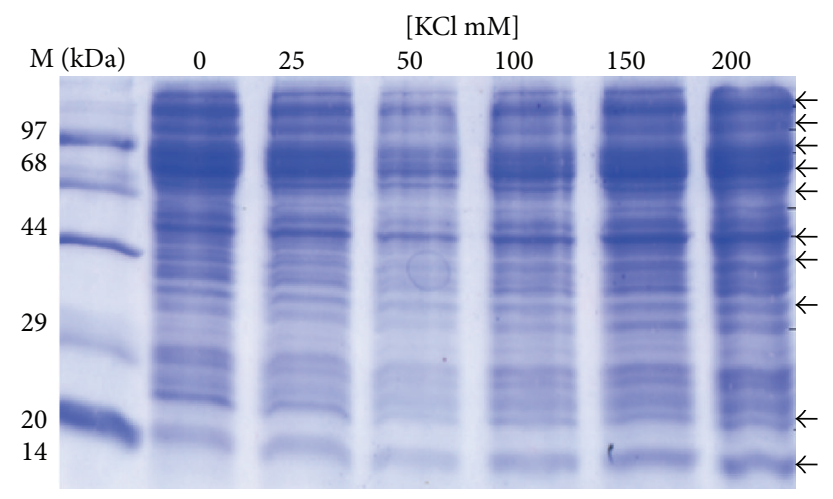

FIGURE 5: Effect of concentration of $\mathrm{KCl}$ on protein profile of membrane-bound fraction (set 2). The protein profile of the mitochondrial membrane-bound fraction shows polypeptides of $150 \mathrm{kDa}, 120 \mathrm{kDa}, 100 \mathrm{kDa}, 97 \mathrm{kDa}, 93 \mathrm{kDa}, 88 \mathrm{kDa}, 67 \mathrm{kDa}, 50 \mathrm{kDa}, 48 \mathrm{kDa}, 44 \mathrm{kDa}, 33 \mathrm{kDa}$, $23 \mathrm{kDa}$, and $20 \mathrm{kDa}$.

\section{Results}

3.1. The Optimal Level of Widely Used $\mathrm{KCl}$ Induces Leakage of Mitochondrial Proteins. The analysis of protein profile of the cytosolic and the mitochondrial fractions showed increased intensities of bands of $110 \mathrm{kDa}, 97 \mathrm{kDa}, 70 \mathrm{kDa}$, $68 \mathrm{kDa}, 44 \mathrm{kDa}, 38 \mathrm{kDa}, 28 \mathrm{kDa}, 25 \mathrm{kDa}$, and $23 \mathrm{kDa}$ in the cytosolic fraction (Figure 2) while lower levels of $110 \mathrm{kDa}$, $97 \mathrm{kDa}, 70 \mathrm{kDa}, 68 \mathrm{kDa}, 66 \mathrm{kDa}, 44 \mathrm{kDa}, 20 \mathrm{kDa}$, and $14 \mathrm{kDa}$ proteins were observed in the mitochondrial fraction (Figure 3). In second set of experiment (E2) progressive decrease in intensities of $110 \mathrm{kDa}, 96 \mathrm{kDa}, 70 \mathrm{kDa}, 23 \mathrm{kDa}$, and $20 \mathrm{kDa}$ was observed with increasing concentration of $\mathrm{KCl}$ (Figure 4). However, higher intensities of $150 \mathrm{kDa}, 120 \mathrm{kDa}$, $100 \mathrm{kDa}, 97 \mathrm{kDa}, 93 \mathrm{kDa}, 88 \mathrm{kDa}, 67 \mathrm{kDa}, 50 \mathrm{kDa}, 48 \mathrm{kDa}$, $44 \mathrm{kDa}, 33 \mathrm{kDa}, 23 \mathrm{kDa}$, and $20 \mathrm{kDa}$ bands in mitochondrial membrane-bound fraction was (Figure 5) evident with increasing $\mathrm{KCl}$ concentration. 


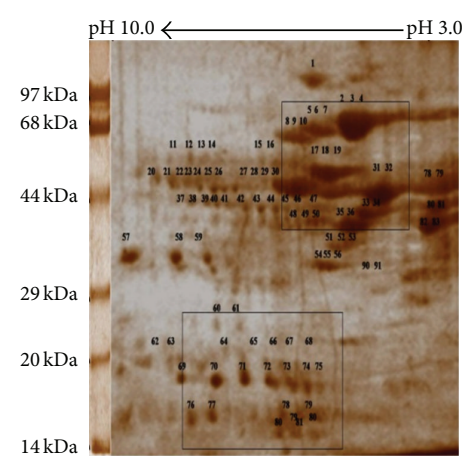

(a)

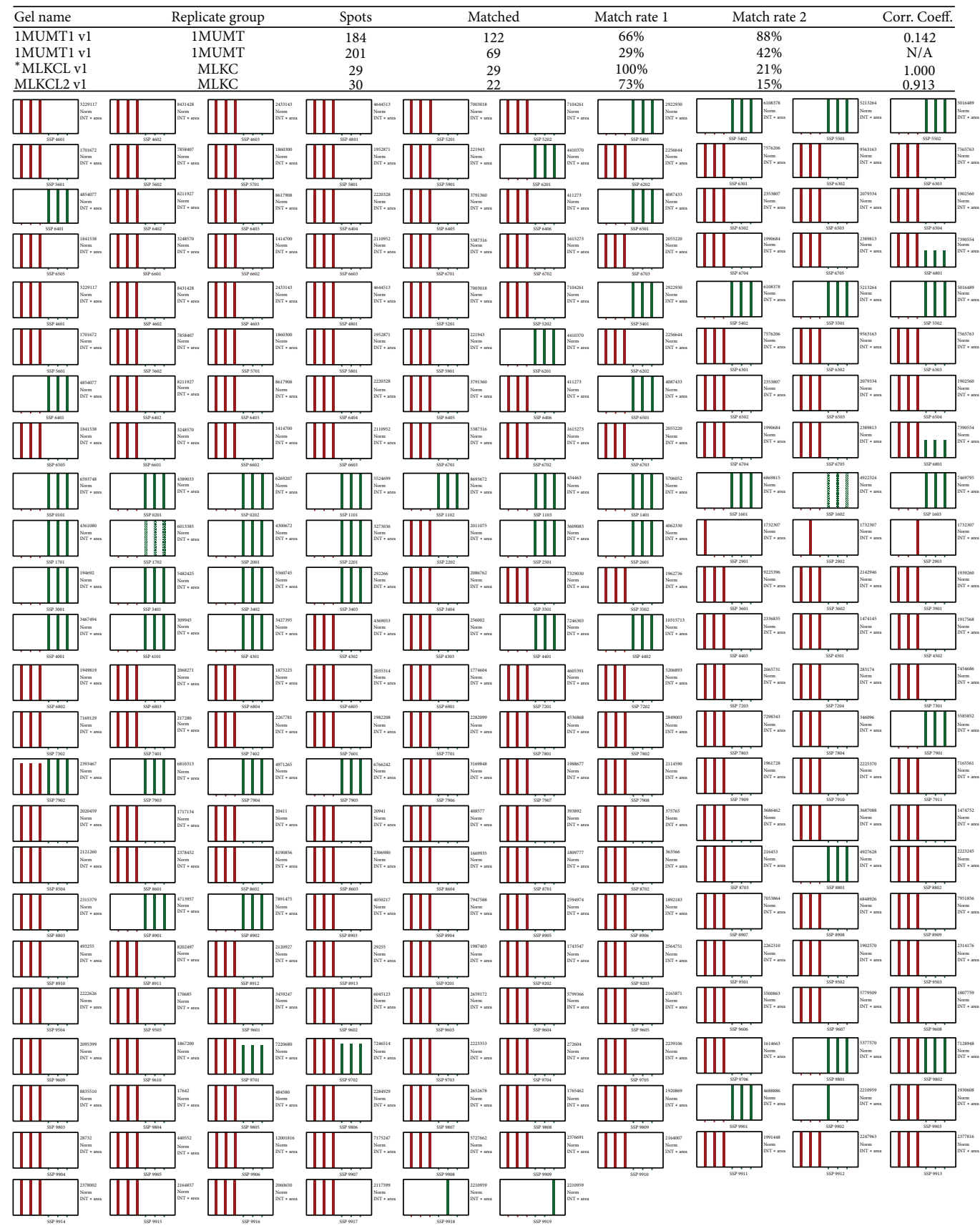

(b) 


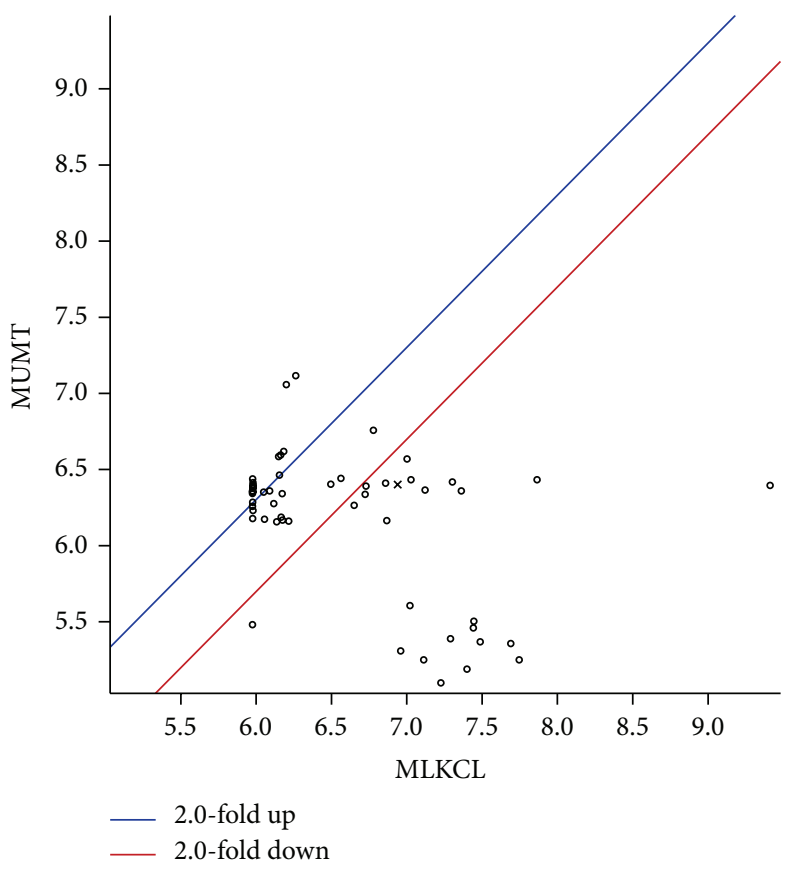

(c)

FIGURE 6: (a) Effect of concentration of $\mathrm{KCl}$ on 2D protein profile of total mitochondrial fraction. Selected area in rectangle (upper rectangle and lower rectangle) shows the variation of spots with the effect of $\mathrm{KCl}$. (b) Spot intensity analysis of 2D protein profile of mitochondrial matrix fraction (MLW) in comparison to protein profile of mitochondrial membrane-bound fraction (MLKCl). (c) Correlation graph analysis of 2D protein profile of mitochondrial matrix fraction (MLW) in comparison to mitochondrial membrane bound fraction ( $\mathrm{MLKCl)}$.

The analysis of 2D gel profile (Figures 6-8) revealed that the intensities of protein spots in matrix fraction were less than the membrane-bound fractions. Protein spots around pI3-6 and $44-97 \mathrm{kDa}$ (upper rectangle) were significantly altered as compared to group of spots below $44 \mathrm{kDa}$ and pI4-7 (lower rectangle). The number and intensities of spots were more in the membrane-bound fraction (Figure 8) than mitochondrial matrix fraction (Figure 7). Similarly, PDQuest analysis of the total mitochondrial matrix versus $\mathrm{KCl}$ solubilised fraction showed only $40 \%$ matching of the spots from the $\mathrm{KCl}$ solubilised fraction. However, the analysis of washed mitochondrial matrix versus $\mathrm{KCl}$ showed $60 \%$ matching with control gel. The intensities of several spots in the KCl solubilised fraction were higher by 2 -fold in total mitochondrial and washed mitochondrial matrix fraction. The analysis of proteins represents translocase of outer mitochondrial membrane complex (TOM) and translocase of inner mitochondrial membrane complex (TIM), Bcl2, VDAC, Porins, and Acyl CoA Synthetase $(76 \mathrm{kDa})$ and Hexokinase I $(100 \mathrm{kDa})$; inner-membrane space proteins Cytochrome-C oxidase $(14 \mathrm{kDa})$, inner-mitochondrial membrane proteins such as Succinate Dehydrogenase $(70 \mathrm{kDa}$ and $27 \mathrm{kDa})$, Aconitase $(44 \mathrm{kDa})$, ATP Synthatase $(56 \mathrm{kDa}$ and $30 \mathrm{kDa}), \mathrm{NADH}$ Dehydrogenase $(51 \mathrm{kDa}, 30 \mathrm{kDa}$ and $17 \mathrm{kDa})$, and Carnitine Acyl transferase I $(88 \mathrm{kDa})$ represent association with mitochondrial membrane. However, Citrate Synthetase $(44 \mathrm{kDa})$, Isocitrate Dehydrogenase $(16 \mathrm{kDa}), \alpha$-keto Dehydrogenase I
$(114 \mathrm{kDa}), \alpha$-keto Dehydrogenase II $(52 \mathrm{kDa})$, Fumarate Dehydrogenase ( $55 \mathrm{kDa})$, Malate Dehydrogenase II (33 kDa), Pyruvate Dehydrogenase $(93 \mathrm{kDa})$, Fructose bisphosphate aldolase $\mathrm{B}(48 \mathrm{kDa})$, and PEP Carboxykinase $(75 \mathrm{kDa})$ belong to mitochondrial matrix proteins (Figure 8 ).

3.2. Ultrastructural Changes in the Mitochondrial Integrity. The ultrastructural analysis by TEM indicates $\mathrm{KCl}$-dependent swelling of mitochondria and disruption of the outer mitochondrial membrane (Figures 9(a)-9(d)). The deformities in the cristae of KCl-treated mitochondria (Figures 9(c), 9(d), and 9(e)) were evident as compared to control.

\section{Discussion}

Observations provide insight into alterations in the integrity of mitochondria under routinely used concentration of potassium chloride $(\mathrm{KCl})$. The analysis of unique spots of mitochondrial membrane-bound fraction and data-mining of proteins around $\mathrm{pI} 3-6$ and $44-97 \mathrm{kDa}$ show significant alteration of proteins associated with enzymes and proteins of oxidative phosphorylation, pyruvate oxidation, and $\beta$ oxidation (Table 1). The observation indicates impact of $\mathrm{KCl}$ on the outer membrane-associated proteins or loosely associated proteins from $17 \mathrm{kDa}$ to $50 \mathrm{kDa}$. These proteins appear to be Porins and transporters proteins. However, the enrichment of high molecular weight spots and medium to 


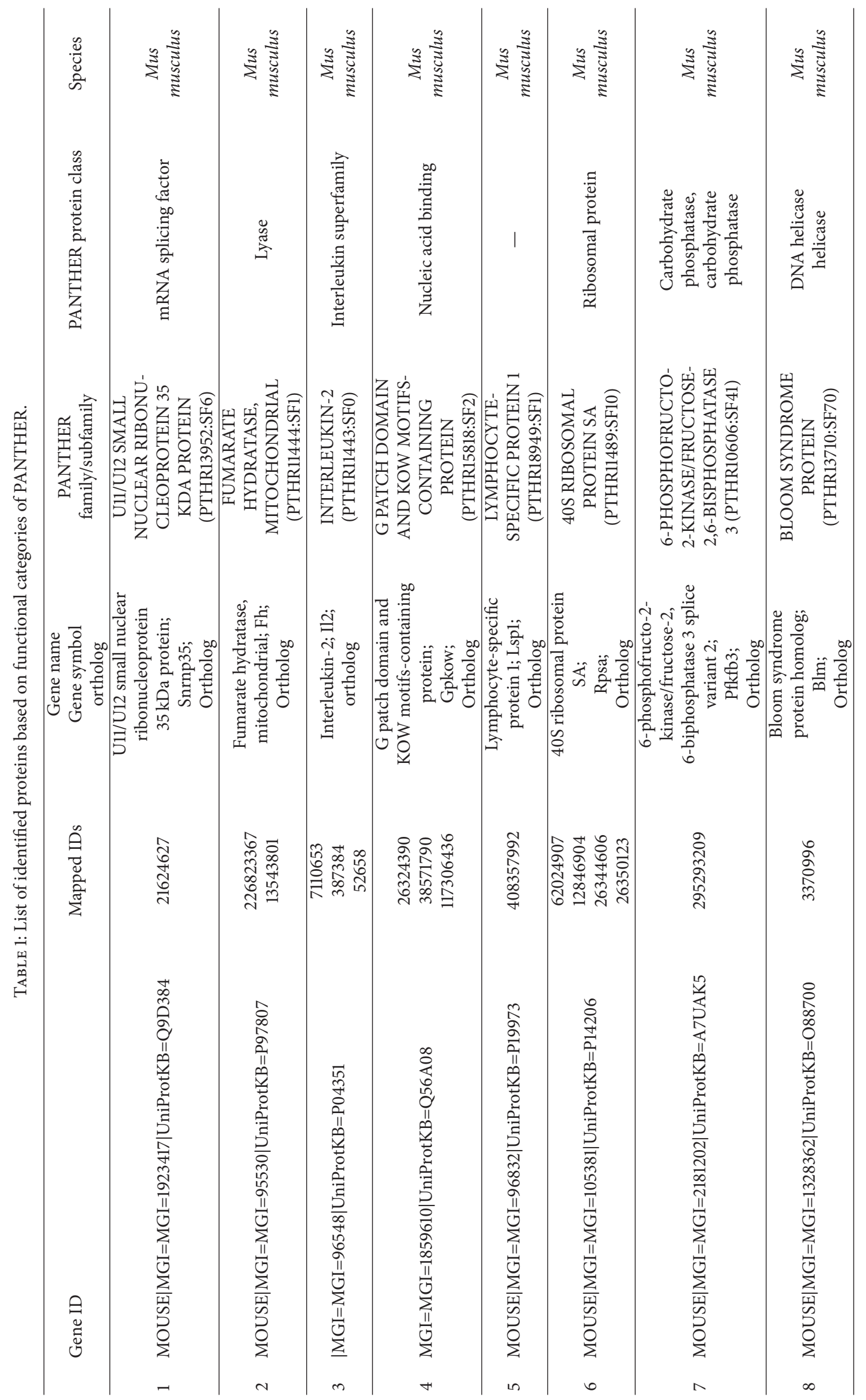




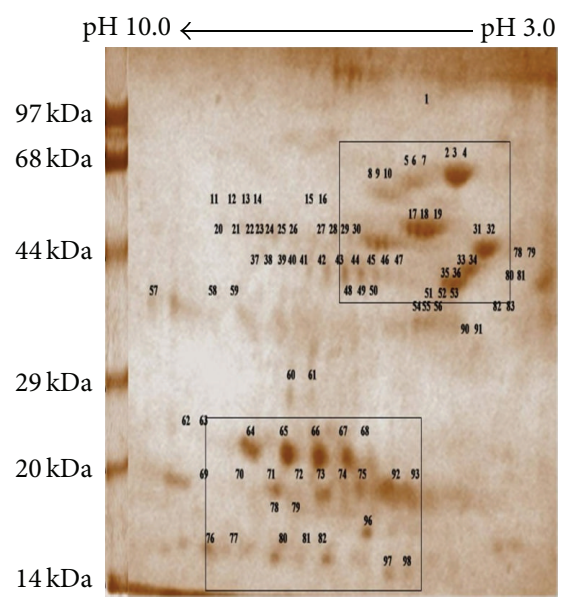

(a)

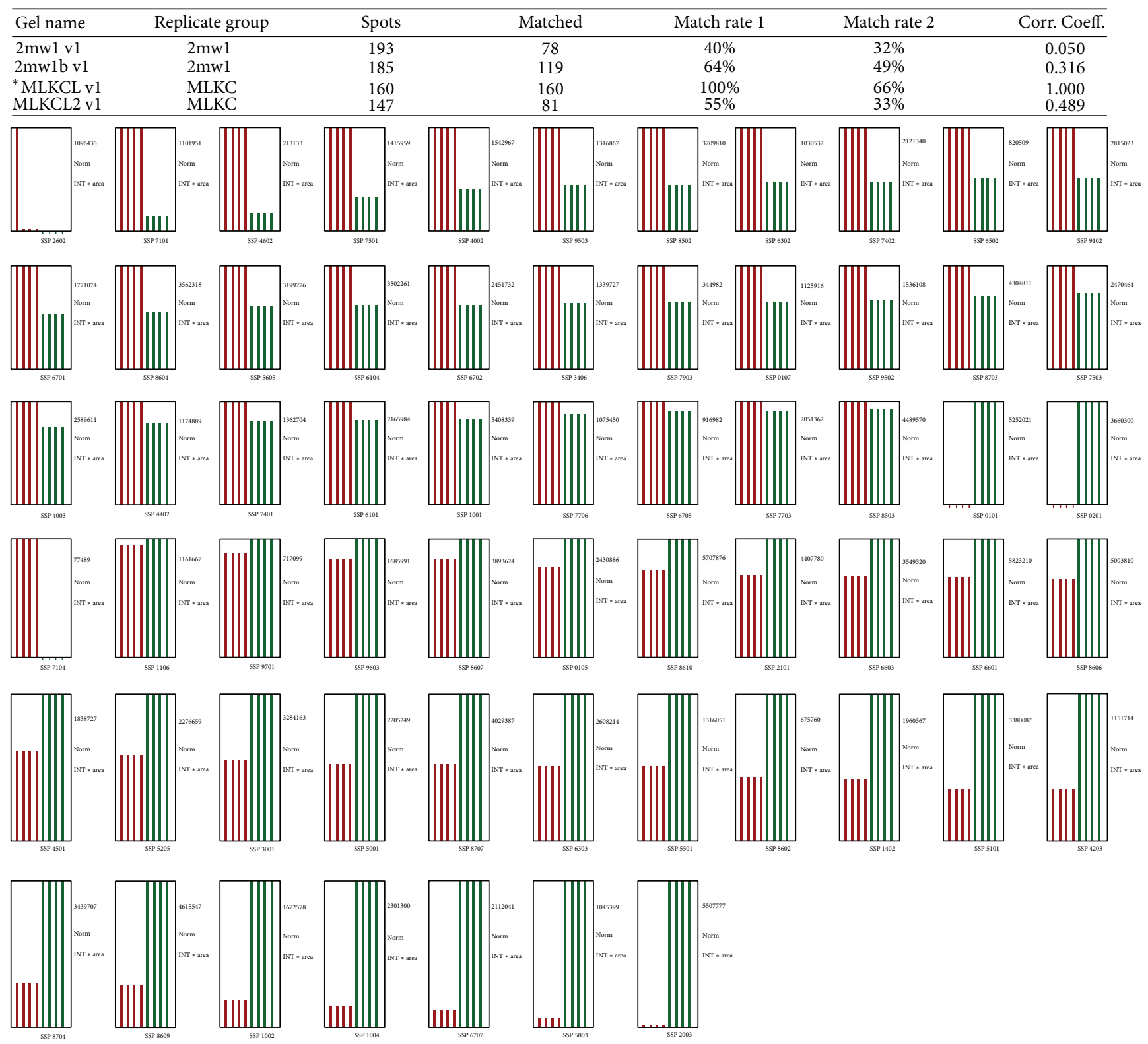

(b)

FIGURE 7: Continued. 


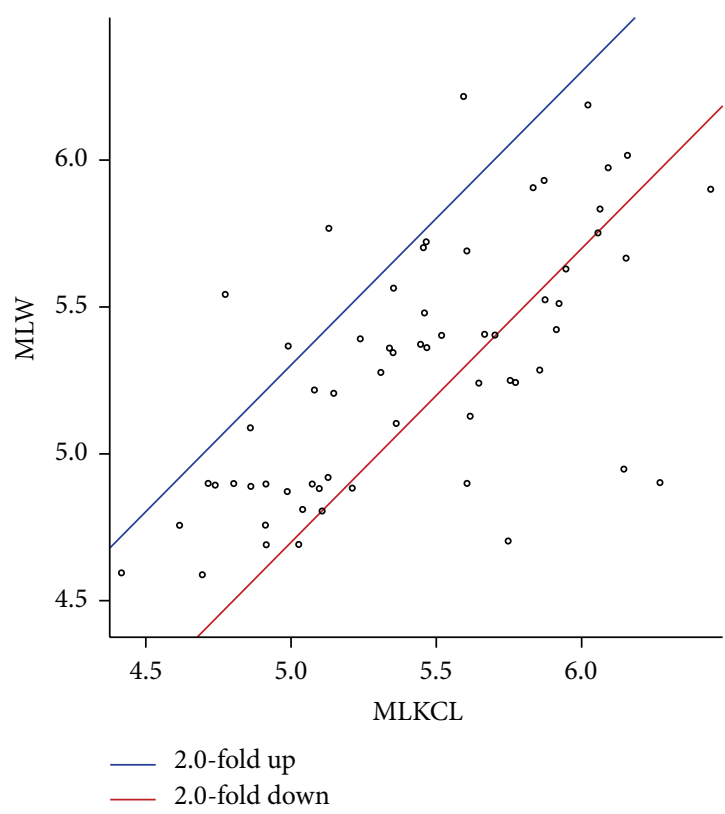

(c)

Figure 7: (a) Effect of concentration of $\mathrm{KCl}$ on 2D protein profile of mitochondrial membrane bound fraction. Selected area in rectangle (upper rectangle and lower rectangle) shows the variation of spots with the effect of $\mathrm{KCl}$. (b) MS spectra of the unique spot of mitochondrial membrane-bound fraction. (c) Analysis of biological functions of proteins identified by MALDI/MSMS and their classification represented as pie chart.

lower molecular weight spots indicates KCl-induced damage of mitochondrial integrity. The $2 \mathrm{D}$ analysis shows two fold increase in the intensity of membrane-bound fraction (Figure 8) in comparison to total mitochondria (Figure 6) and mitochondrial matrix (Figure 7). The optimal level of the $\mathrm{KCl}$ has been explained to breach the electrostatic bonds of the proteins to facilitate solubilization of proteins (Figure 1(a)) but the higher concentration of $\mathrm{KCl}$ may disrupt integrity of the membrane by modifying polarization of lipid bilayer, permeabilization of the mitochondrial membrane, and shrinkage of mitochondrial membrane (Figure 1(b)). Similarly salt-dependent modulation of Hexokinase-I and Cytochrome-C [9], integrity of the organelle membrane [2, 10-12], opening of mitochondrial permeability transition pore $[6,13,14]$, and salt-induced $\mathrm{pH}$ homeostasis [7] have also been explained. The monovalent salts were also suggested to alter permeability of the membrane characteristics $[4,5,10]$.

On data-mining, modulated proteins like translocases, Porins, and Acyl CoA Synthetase and Hexokinase, Cytochrome-C oxidase, Succinate Dehydrogenase, Aconitase, ATP Synthatase, and NADH Dehydrogenase represent association with mitochondrial membrane (Figure 8). However, Citrate Synthetase, Isocitrate Dehydrogenase, $\alpha$-keto Dehydrogenases, Fumarate Dehydrogenase, Malate Dehydrogenase, Pyruvate Dehydrogenase, Fructose bisphosphate aldolase B, and PEP Carboxykinase belong to mitochondrial matrix. The alteration in the ultrastructure of mitochondria after the treatment of $\mathrm{KCl}$ supports mitochondrial swelling, altered morphology of cristae, and disruption in outer mitochondrial membrane as compared to control (Figure 9(a)). The $\mathrm{KCl}$ induced damage of mitochondrial outer membrane and extraction of outer mitochondrial membrane-associated proteins were also suggested by the disruption of electrostatic force between lipid and protein molecules. Similarly, tissue-specific mitochondrial proteome analysis was also identified [15]. Proteins like Fumarate hydratase and Fructose 2,6-bisphosphate aldolase B were modulated significantly by the $\mathrm{KCl}$.

\section{Conclusion}

Potassium chloride, a monovalent salt and common component of different extraction procedures, affects mitochondrial integrity and proteomics of mitochondria. It affects both matrix and membrane-bound proteins.

\section{Conflict of Interests}

The authors declare that they have no conflict of interests.

\section{Acknowledgment}

Suman Mishra acknowledged the Research Fellowship in Science for Meritorious Students, U.G.C. New Delhi. Rajnikant Mishra acknowledges financial supports from BHU, UGCCAS, UGC-UPE, and BHU-DBT-ISLS. They also appreciate 


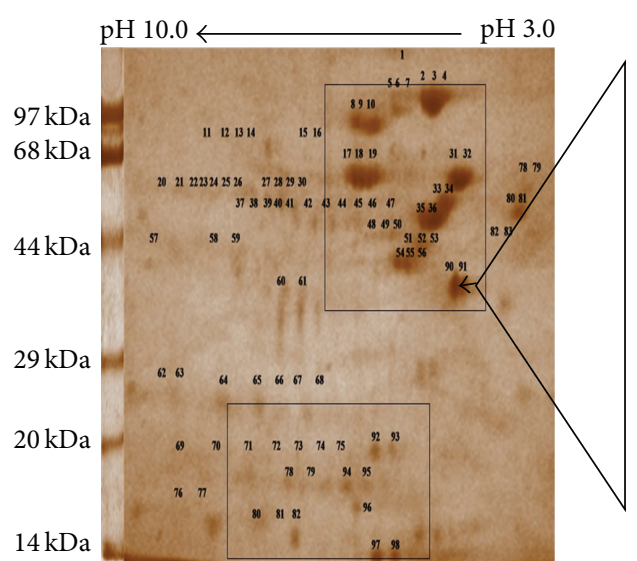

(a)

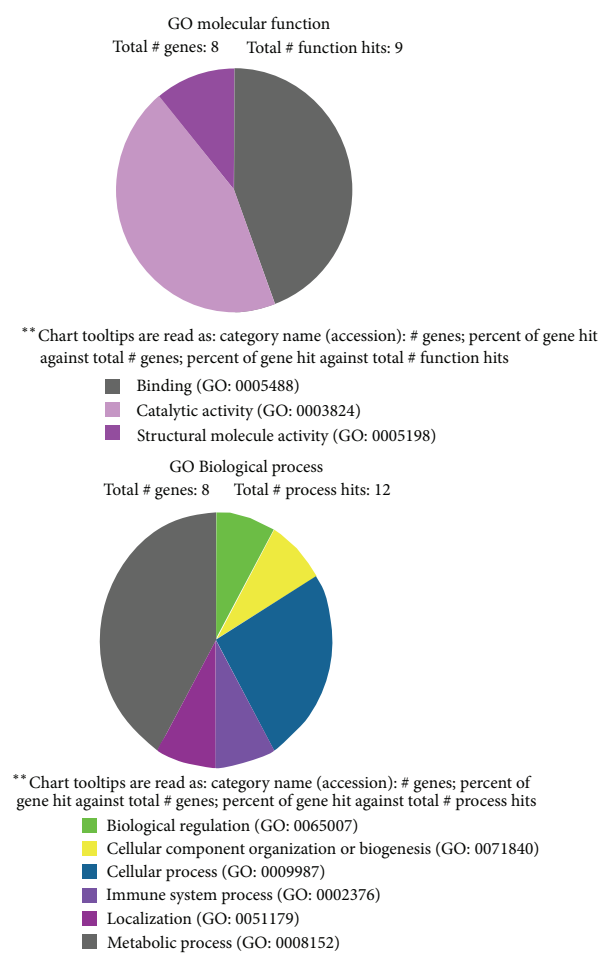

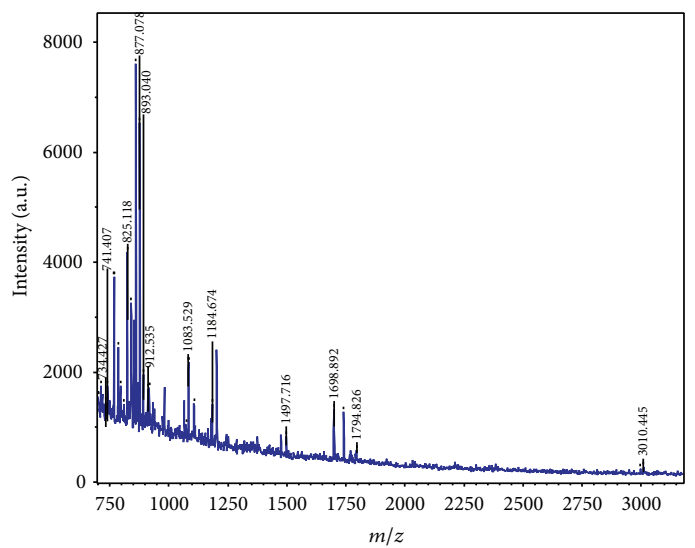

(b)

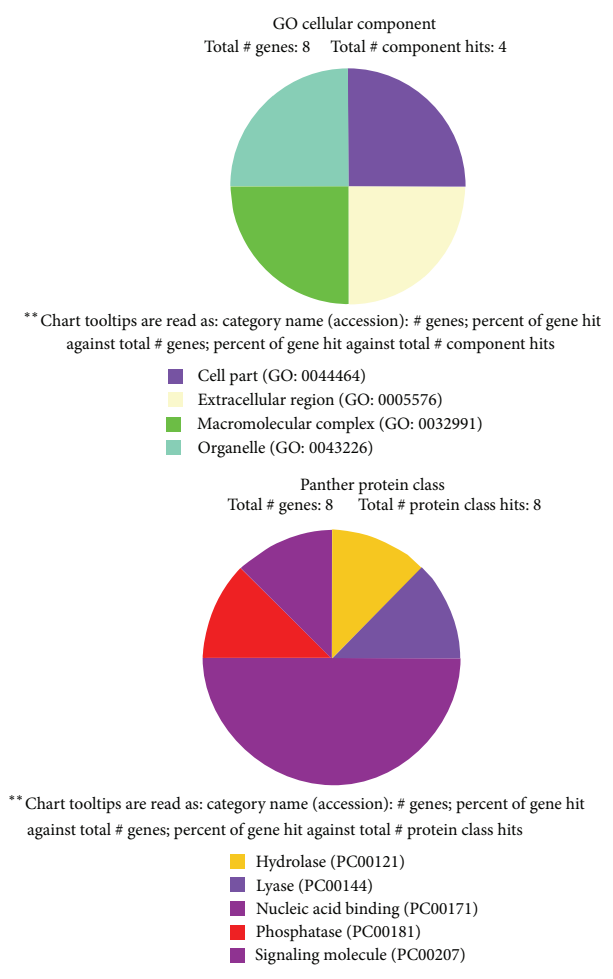

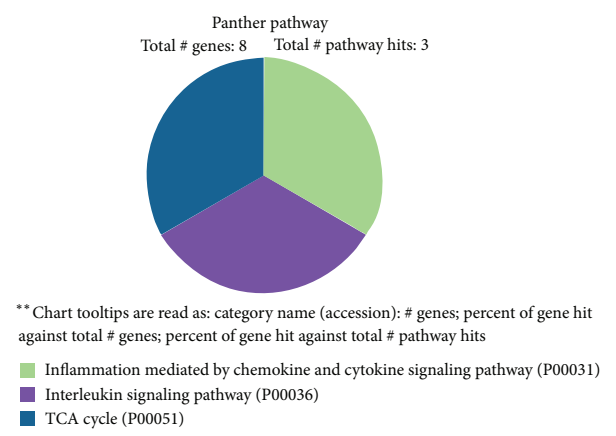

(c)

Figure 8: (a) Effect of concentration of $\mathrm{KCl}$ on 2D protein profile of mitochondrial membrane-bound fraction. Selected area in rectangle (upper rectangle and lower rectangle) shows the variation of spots with the effect of KCl. (b) MS spectra of the unique spot of mitochondrial membrane-bound fraction. (c) Analysis of biological functions of proteins identified by MALDI/MSMS and their classification represented as pie chart. 

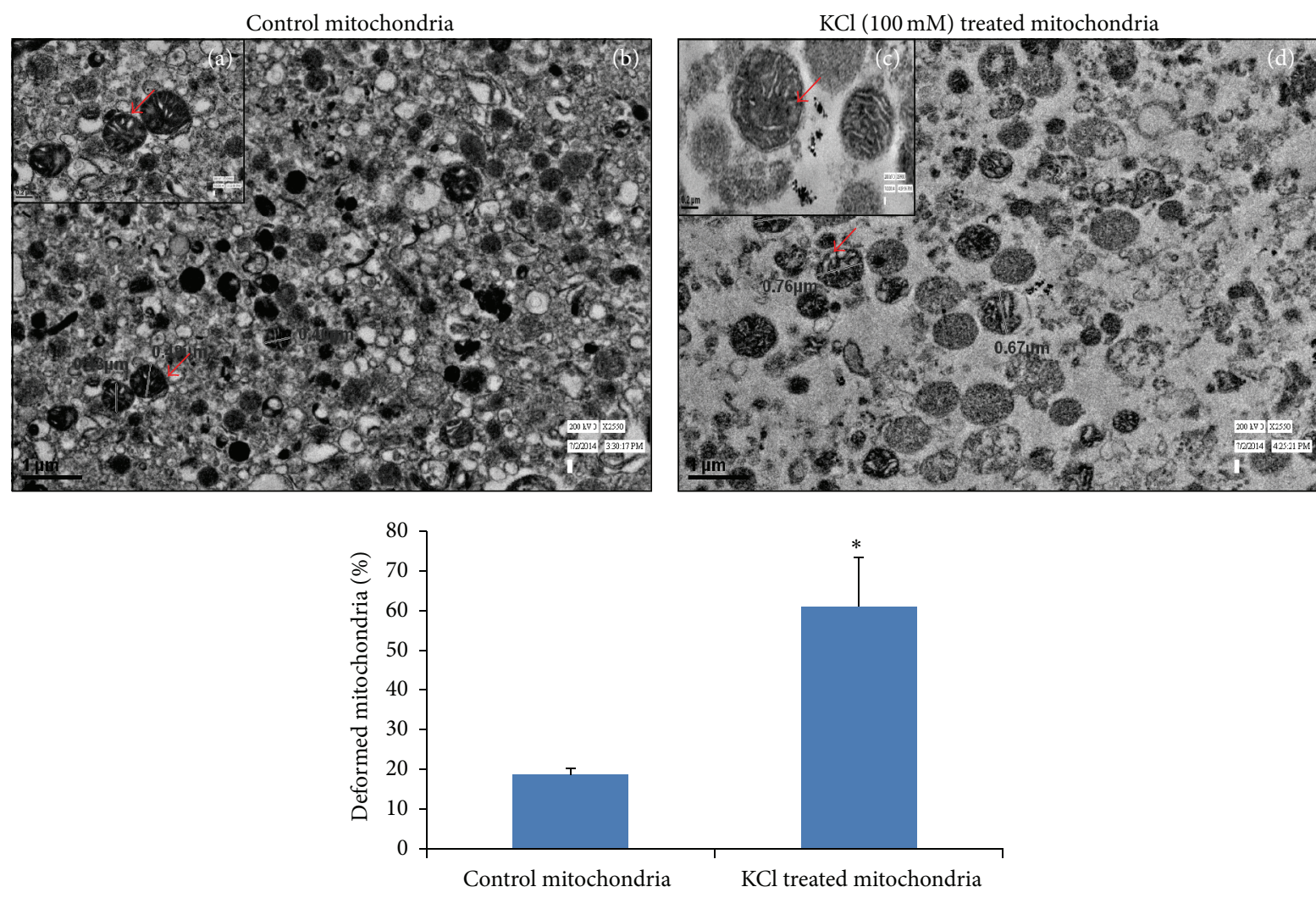

(e)

FIGURE 9: Transmission electron microscopic analysis of mitochondrial surface before and after the treatment of KCl showed mitochondrial swelling, altered morphology of cristae, and disruption in outer mitochondrial membrane after $\mathrm{KCl}$ treatment. (a) Ultrastructure of control mitochondria; (b) enlarged micrograph of isolated mitochondria; (c) ultrastructure of $\mathrm{KCl}$ treated mitochondria; (d) enlarged micrograph of $\mathrm{KCl}$ treated mitochondria; (e) histogram of \% of deformed mitochondria of control and $\mathrm{KCl}$ treated mitochondrial fraction (percentage is calculated by dividing number of deformed mitochondria by total number of mitochondria). $*$ denoted the significance level $p<0.05$ compared to control.

AIIMS, New Delhi, for extending TEM facility for this study.

\section{References}

[1] J. Yannariello-Brown and P. H. Weigel, "Detergent solubilization of the endocytic $\mathrm{Ca}^{2+}$-independent hyaluronan receptor from rat liver endothelial cells and separation from a $\mathrm{Ca}^{2+}$-dependent hyaluronan-binding activity," Biochemistry, vol. 31, no. 2, pp. 576-584, 1992.

[2] A. B. Cubitt and M. C. Gershengorn, "Characterization of a saltextractable phosphatidylinositol synthase from rat pituitarytumour membranes," Biochemical Journal, vol. 257, no. 3, pp. 639-644, 1989.

[3] P. Bernardi, "Mitochondrial transport of cations: channels, exchangers, and permeability transition," Physiological Reviews, vol. 79, no. 4, pp. 1127-1155, 1999.

[4] R. A. Böckmann, A. Hac, T. Heimburg, and H. Grubmüller, "Effect of sodium chloride on a lipid bilayer," Biophysical Journal, vol. 85, no. 3, pp. 1647-1655, 2003.

[5] H. I. Petrache, S. Tristram-Nagle, D. Harries, N. Kuĉerka, J. F. Nagle, and V. A. Parsegian, "Swelling of phospholipids by monovalent salt," Journal of Lipid Research, vol. 47, no. 2, pp. 302-309, 2006.

[6] A. P. Halestrap, "Calcium, mitochondria and reperfusion injury: a pore way to die," Biochemical Society Transactions, vol. 34, no. 2, pp. 232-237, 2006.

[7] T. Boczek, M. Lisek, B. Ferenc et al., "Plasma membrane $\mathrm{Ca}^{2+}$ ATPase isoforms composition regulates cellular $\mathrm{pH}$ homeostasis in differentiating PC12 cells in a manner dependent on cytosolic $\mathrm{Ca}^{2+}$ elevations," PLoS ONE, vol. 9, no. 7, Article ID e102352, 2014.

[8] M. M. Bradford, "A rapid and sensitive method for the quantitation of microgram quantities of protein utilizing the principle of protein-dye binding," Analytical Biochemistry, vol. 72, no. 1-2, pp. 248-254, 1976.

[9] M. S. Segal and E. Beem, "Effect of pH, ionic charge, and osmolarity on cytochrome $c$-mediated caspase-3 activity," American Journal of Physiology-Cell Physiology, vol. 281, no. 4, pp. C1196C1204, 2001.

[10] L. Michea, C. Combs, P. Andrews, N. Dmitrieva, and M. B. Burg, "Mitochondrial dysfunction is an early event in high$\mathrm{NaCl}$-induced apoptosis of mIMCD3 cells," The American Journal of Physiology-Renal Physiology, vol. 282, no. 6, pp. F981-F990, 2002. 
[11] F. Fieni, A. Parkar, T. Misgeld et al., "Voltage-dependent inwardly rectifying potassium conductance in the outer membrane of neuronal mitochondria," Journal of Biological Chemistry, vol. 285, no. 35, pp. 27411-27417, 2010.

[12] R. T. Uren, G. Dewson, C. Bonzon, T. Lithgow, D. D. Newmeyer, and R. M. Kluck, "Mitochondrial release of pro-apoptotic proteins: electrostatic interactions can hold cytochrome $\mathrm{c}$ but not Smac/DIABLO to mitochondrial membranes," The Journal of Biological Chemistry, vol. 280, no. 3, pp. 2266-2274, 2005.

[13] T. E. Gunter, L. Buntinas, G. Sparagna, R. Eliseev, and K. Gunter, "Mitochondrial calcium transport: mechanisms and functions," Cell Calcium, vol. 28, no. 5-6, pp. 285-296, 2000.

[14] O. Vergun and I. J. Reynolds, "Fluctuations in mitochondrial membrane potential in single isolated brain mitochondria: modulation by adenine nucleotides and $\mathrm{Ca}^{2+}$, Biophysical Journal, vol. 87, no. 5, pp. 3585-3593, 2004.

[15] S. Techritz, S. Lützkendorf, E. Bazant, S. Becker, J. Klose, and M. Schuelke, "Quantitative and qualitative 2D electrophoretic analysis of differentially expressed mitochondrial proteins from five mouse organs," Proteomics, vol. 13, no. 1, pp. 179-195, 2013. 

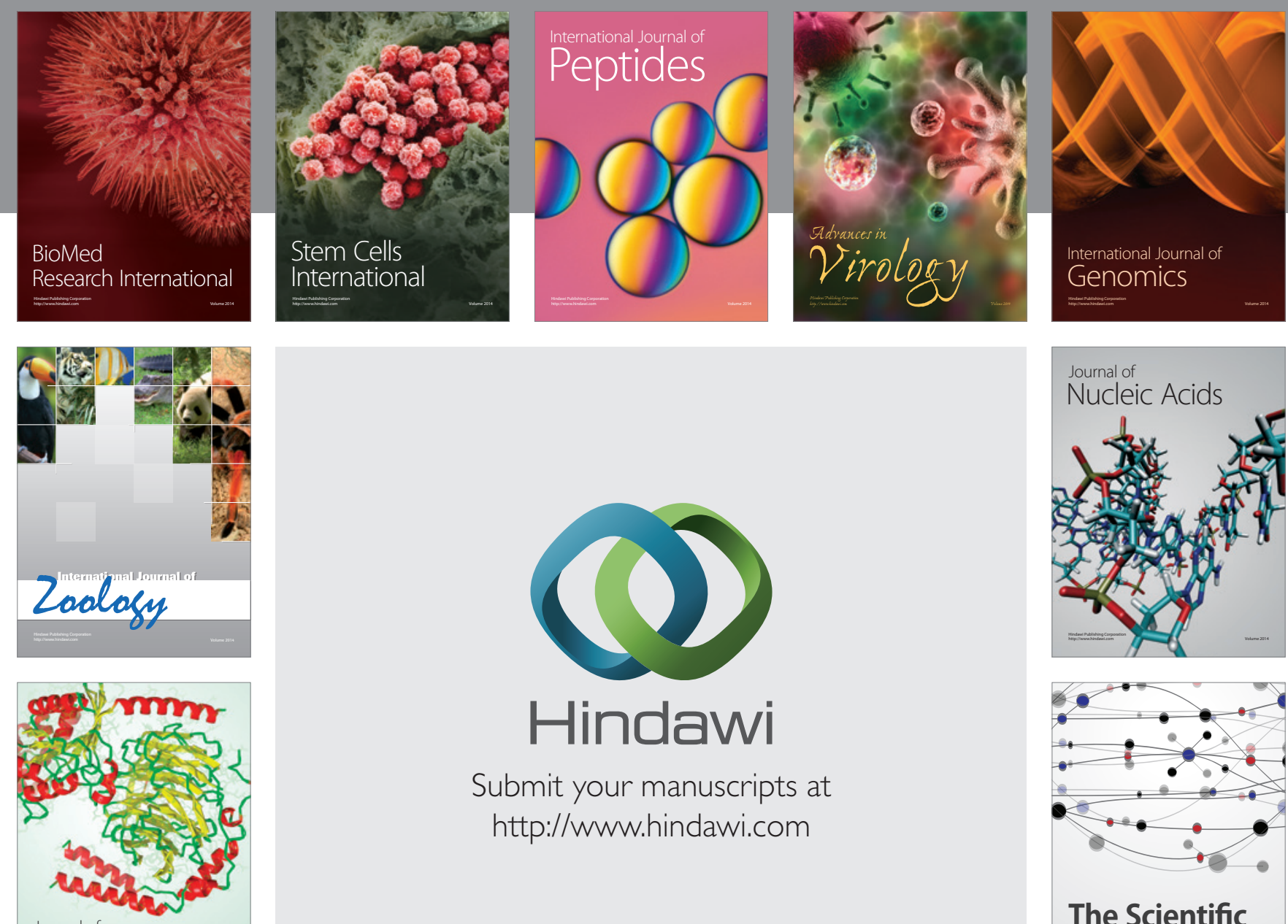

Submit your manuscripts at

http://www.hindawi.com

Journal of
Signal Transduction
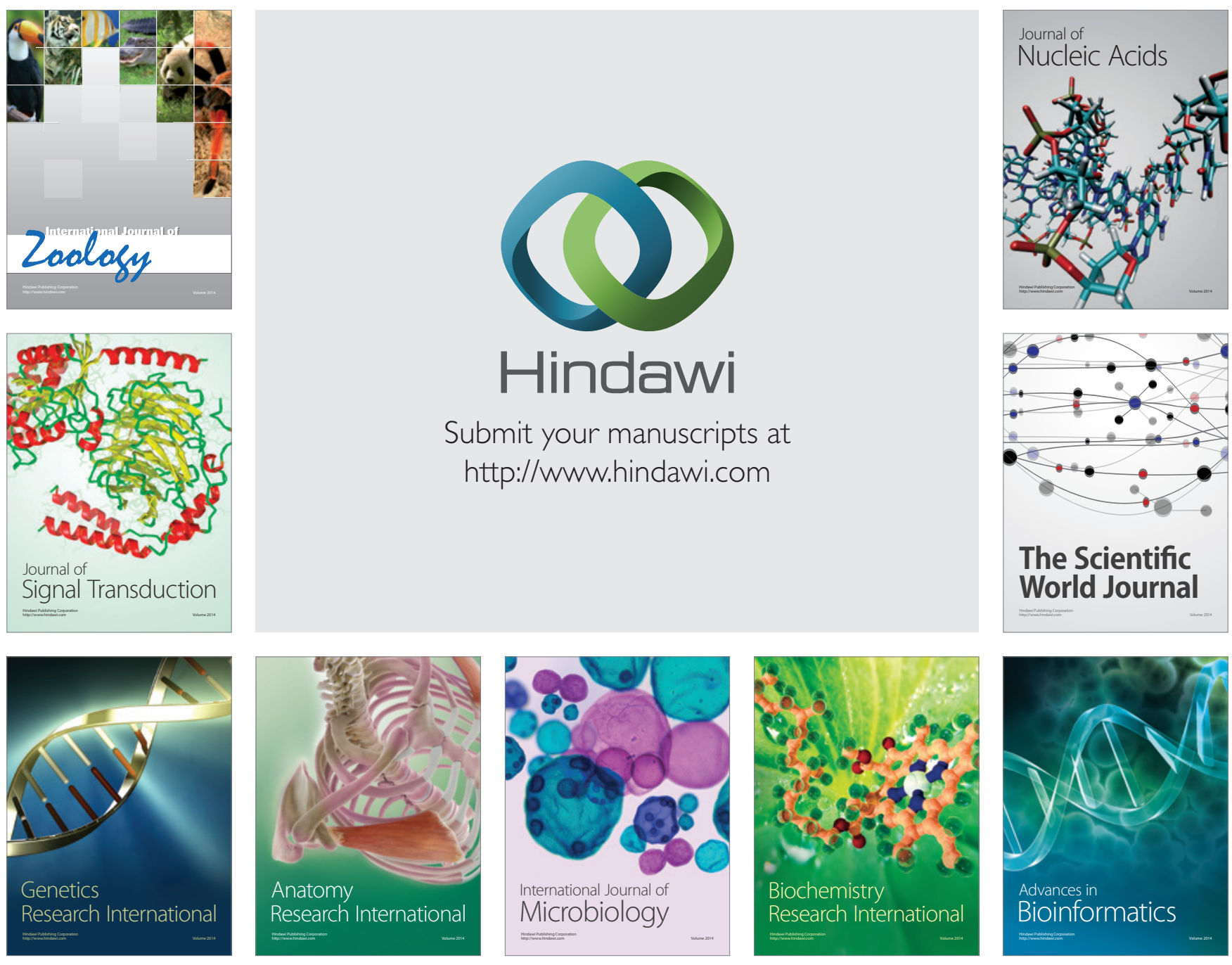

The Scientific World Journal
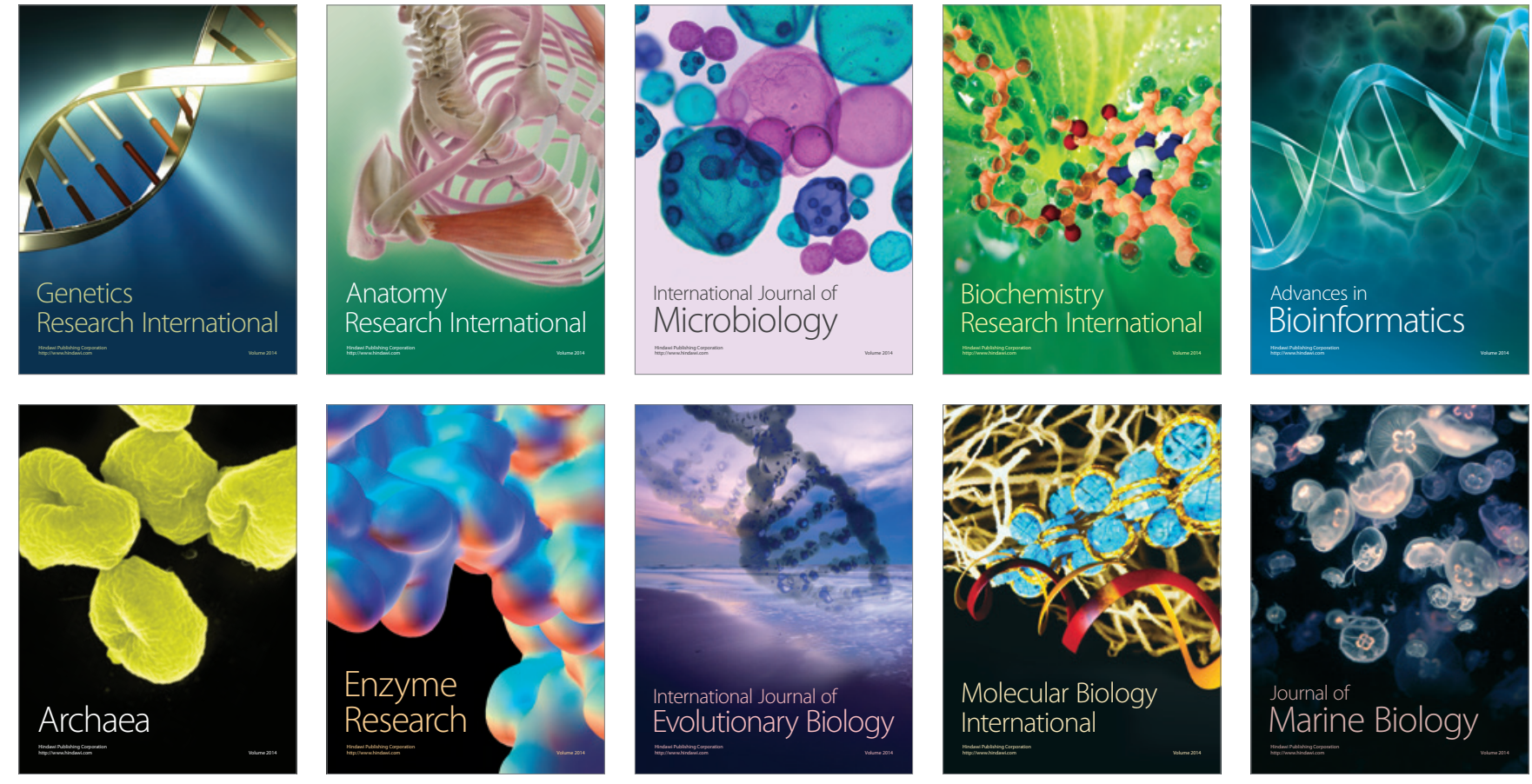